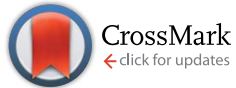

Cite this: RSC Adv., 2015, 5, 24132

Received 6th December 2014 Accepted 19th February 2015

DOI: $10.1039 / c 4 r a 15885 g$

www.rsc.org/advances

\title{
A unique strategy towards high dielectric constant and low loss with multiwall carbon nanotubes anchored onto graphene oxide sheets
}

\author{
Sourav Biswas, $\uparrow$ Goutam Prasanna Kar, $\uparrow$ Deepshikha Arora and Suryasarathi Bose* \\ Multiwall carbon nanotubes (MWNTs) were anchored onto graphene oxide sheets (GOs) via diazonium \\ and $\mathrm{C}-\mathrm{C}$ coupling reactions and characterized by spectroscopic and electron microscopic \\ techniques. The thus synthesized MWNT-GO hybrid was then melt mixed with 50/50 polyamide6- \\ maleic anhydride-modified acrylonitrile-butadiene-styrene (PA6-mABS) blend to design materials with \\ high dielectric constant $\left(\varepsilon^{\prime}\right)$ and low dielectric loss. The phase morphology was studied by SEM and it \\ was observed that the MWNT-GO hybrid was selectively localized in the PA6 phase of the blend. The \\ $\varepsilon^{\prime}$ scales with the concentration of MWNT-GO in the blends, which interestingly showed a very low \\ dielectric loss $(<0.2)$ making them potential candidate for capacitors. In addition, the dynamic storage \\ modulus scales with the fraction of MWNT-GO in the blends, demonstrating their reinforcing \\ capability as well.
}

\section{Introduction}

Polymeric composites with high dielectric constant and low dielectric loss have received considerable attention in the recent past. ${ }^{1-4}$ They have been explored for various applications in high energy storage devices, electronics and other industries. ${ }^{5-7}$ Dielectric properties arise from the uneven displacement of electrons under an external electric field. Complex permittivity is expressed as $\varepsilon^{*}=\varepsilon^{\prime}-\mathrm{i} \varepsilon^{\prime \prime}$, where $\varepsilon^{\prime}$ and $\varepsilon^{\prime \prime}$ are the real and imaginary parts of the complex permittivity. ${ }^{8-10}$ According to the Kramers-Kronig relation, $\varepsilon^{\prime}$ and $\varepsilon^{\prime \prime}$ depend on the frequency, $\omega$, of the applied electric field, and this is expressed as KramersKronig relation, ${ }^{11}$

$$
\varepsilon^{\prime}(\omega)=\varepsilon_{0}+\frac{2}{\pi} \int_{0}^{\infty} \frac{u \varepsilon^{\prime \prime}(u)}{u^{2}-\omega^{2}} \mathrm{~d} u
$$

The real part of the permittivity is expressed as $\varepsilon^{\prime}=\varepsilon_{0} \varepsilon_{\mathrm{r}}$, where $\varepsilon_{0}$ is the vacuum permittivity $\left(8.85 \times 10^{-12} \mathrm{~F} \mathrm{~m}^{-1}\right)$ and $\varepsilon_{\mathrm{r}}$ is the relative permittivity of the material. Higher values of $\varepsilon^{\prime}$ indicate the material's ability to store energy under an applied electrical field. The imaginary part of the permittivity $\left(\varepsilon^{\prime \prime}\right)$ is the dielectric loss. It is envisaged that under the influence of an external electric field, part of the electrical energy is dissipated as heat due to charge hopping. Hence, for better performance, this dielectric loss needs to be

Department of Materials Engineering, Indian Institute of Science, Bangalore-560012, India. E-mail: sbose@materials.iisc.ernet.in; Tel: +91-80-2293 3407

$\dagger$ GPK and SB made equal contribution to this work. minimized. The energy stored by a parallel plate capacitor is given by

$$
W=\frac{1}{2} C V_{\mathrm{br}}^{2}
$$

where $V_{\mathrm{br}}$ is the breakdown voltage and $C$ is the capacitance, given by

$$
C=\varepsilon_{0} \varepsilon_{\mathrm{r}} \frac{A}{l}
$$

$A$ is the area and $l$ is thickness of the parallel plate capacitor. Hence, the volumetric energy density is given by

$$
W^{\prime}=\frac{1}{2} \varepsilon_{0} \varepsilon_{\mathrm{r}} E_{\mathrm{br}}^{2}
$$

where $E_{\mathrm{br}}=\frac{V_{\mathrm{br}}}{l}$ is the breakdown field strength.

Polymers generally have a very low dielectric constant $(<10)$ but high breakdown field strength. ${ }^{6}$ On the other hand, ferroelectric ceramic particles have a very high dielectric constant $\left(\varepsilon^{\prime}\right)$ but very low breakdown strength. ${ }^{12}$ So, a high $\varepsilon^{\prime}$ and low loss can be achieved by incorporating ceramic particles into a polymer matrix. But this strategy usually requires a higher fraction of the ceramic particles and hence produces an unwanted increase of the composite rigidity. ${ }^{13}$ In most other cases the increase of the dielectric constant has been met with relatively high loss tangent values, which is also an important factor while considering materials for capacitor applications. ${ }^{\mathbf{1 4}}$ Due to the addition of ferroelectric ceramic particles, the interfacial polarization is increased..$^{12}$ Hence, it is very difficult to obtain high dielectric permittivity and low loss tangent values at the same time. However, by altering the interfacial interaction 
between the ceramic particles and the polymer matrix, the dielectric constant can be tuned. ${ }^{5}$ So, the surface chemistry of the particles can play an important role in obtaining materials with a high dielectric constant. ${ }^{15,16}$

In the recent past, in view of good electrical and mechanical integrity, carbon-based nanostructures like multiwall carbon nanotubes (MWNTs) and graphene have attracted a great deal of interest for a wide range of applications. ${ }^{17,18}$ MWNTs show relatively high dielectric loss due to energy dissipation. ${ }^{8}$ Recently, reduced graphene oxide sheets (rGO) with partial chlorination were shown to exhibit a high dielectric constant and low dielectric loss, due to the polarizable $\mathrm{C}-\mathrm{Cl}$ bond. ${ }^{19}$

In an attempt to enhance the dielectric constant and reduce the losses, a unique strategy was adopted here by chemically conjugating MWNTs with graphene oxide sheets. The hybrid nanoparticles were then melt blended with 50/50 (wt/wt) PA6mABS blends, which have a low dielectric constant but are mechanically stable. The dielectric, rheological and dynamical mechanical properties were evaluated as a function of the amount of hybrid particles.

\section{Experimental section}

\section{Materials}

PA6 (1022B) was kindly provided by Ube Industries. mABS (Bondyram 6000, MFI $8 \mathrm{~g}$ per $10 \mathrm{~min}$ ) was obtained from Polyram. The pristine MWNTs (NC 7000 of $90 \%$ purity, with an average diameter of $9.5 \mathrm{~nm}$ and an average length of $1.5 \mu \mathrm{m}$ ) were obtained from Nanocyl, Belgium. 4,4'-Methylenedianiline (MDA) was procured from Sigma Aldrich. The solvents like ethanol, tetrahydrofuran (THF), chloroform $\left(\mathrm{CHCl}_{3}\right)$, hydrochloric acid and sodium nitrite $\left(\mathrm{NaNO}_{2}\right)$ were obtained from Merck, India.

\section{Synthesis of $\mathrm{NH}_{2}$ terminated GO}

GO was synthesized by a modified Hummers method as described in our earlier work. ${ }^{20}$ GO- $\mathrm{NH}_{2}$ was synthesized by a nucleophillic substitution reaction. ${ }^{21}$ Typically, $250 \mathrm{mg}$ of GO was suspended in $100 \mathrm{ml}$ of THF and sonicated to exfoliate the sheets. The dispersed GO was then mixed with $250 \mathrm{mg}$ of MDA and refluxed in a oil bath under a nitrogen atmosphere at $80^{\circ} \mathrm{C}$ for $8 \mathrm{~h}$. The solids thus obtained were separated by vacuum filtration, and re-dispersed in $100 \mathrm{ml}$ of ethanol. This was again subjected to vacuum filtration. By repeating this purification cycle for about four times, the obtained solids were dried at $60{ }^{\circ} \mathrm{C}$ under vacuum for $24 \mathrm{~h}$, thus yielding $\mathrm{GO}-\mathrm{NH}_{2}$.

\section{Synthesis of hybrid MWNT-GO}

A diazotization reaction was adopted to synthesize MWNT-GO hybrid structures. ${ }^{22}$ Briefly, the required amount of GO- $\mathrm{NH}_{2}$ was added to $40 \% \mathrm{HCl}$ and bath sonicated. $\mathrm{NaNO}_{2}$ was then added under ice-cold conditions $\left(0-5{ }^{\circ} \mathrm{C}\right)$ with stirring. This step converts GO- $\mathrm{NH}_{2}$ to a diazonium salt of GO. After $2 \mathrm{~h}$ of stirring, the pre-sonicated MWNTs (in dilute $\mathrm{HCl}$ ) were then added under an inert atmosphere. $\mathrm{N}_{2}$ escapes from the diazonium salt of $\mathrm{GO}$ and a MWNT-GO hybrid is formed via a $\mathrm{C}-\mathrm{C}$ coupling reaction. The mixture was then washed by dilute $\mathrm{HCl}$ followed by water and vacuum dried overnight. The same amounts of MWNTs and GO- $\mathrm{NH}_{2}$ were used, thus yielding MWNT-GO (1:1).

\section{Blend preparation}

50/50 (wt/wt) blends of PA6-mABS were prepared with or without MWNT-GO by melt mixing using a Minilab II HAAKE extruder CTW5 (7 cc) at $260{ }^{\circ} \mathrm{C}$ with a rotational speed of $60 \mathrm{rpm}$ for 20 min. ${ }^{23}$ The mixing was performed under $\mathrm{N}_{2}$ atmosphere to prevent oxidative degradation. The samples were pre-dried at $80{ }^{\circ} \mathrm{C}$ in a vacuum oven for $24 \mathrm{~h}$ prior to processing to remove traces of moisture. ${ }^{24}$

\section{Characterizations}

Fourier transform infrared (FTIR) spectroscopy was carried out using Perkin-Elmer GX in the range of $4000-400 \mathrm{~cm}^{-1}$ using a resolution of $4 \mathrm{~cm}^{-1}$ and $\mathrm{KBr}$ pellets.

Transmission Electron Microscopy (TEM) images were acquired using a Tecnai G2 F30 at $300 \mathrm{kV}$.

Morphological analysis for various blends was assessed by using scanning electron microscope on ESEM (environmental scanning electron microscope) at a $10 \mathrm{kV}$ accelerating voltage. The extruded samples were cryofractured in liquid nitrogen. Then the mABS phase was selectively etched out by chloroform at room temperature.

The complex viscosity and storage modulus of the melt state for all the blends were measured by using a Discovery Hybrid Rheometer (DHR-3), TA-instruments, using a parallel plate geometry of a $25 \mathrm{~mm}$ diameter and $1 \mathrm{~mm}$ gap. The extrude strands were vacuum dried at $80{ }^{\circ} \mathrm{C}$ for $12 \mathrm{~h}$ before performing the rheological measurements. Experiments were carried out at a fixed temperature of $260{ }^{\circ} \mathrm{C}$ by varying the frequency from 0.1 to $100 \mathrm{rad} \mathrm{s}^{-1}$ at $1 \%$ strain rate under nitrogen atmosphere to prevent any degradation of the sample.

Dielectric measurements were performed on compressionmolded disks using an Alpha-N Analyzer (Novocontrol, Hundsangen, Germany) in the broad frequency range of $100 \leq \omega \leq$ $10^{6} \mathrm{~Hz}$.

Dynamic mechanical thermal analysis (DMTA) was done on a TA Instruments Q800 Dynamic Mechanical Analyzer on a compression-molded film.

\section{Results and discussion}

\section{Synthesis and characterization of MWNT-GO hybrids}

The MWNTs were grafted onto the GO sheets by a diazotization reaction as described in Scheme 1. Amine groups were introduced onto the GO sheets by reacting with MDA. The amine groups of MDA react with the epoxy groups of the GO. The terminal amine groups thus generated on $\mathrm{GO}-\mathrm{NH}_{2}$ were converted to diazonium salt $\left(-\mathrm{N}_{2}{ }^{+} \mathrm{Cl}^{-}\right)$by reacting with $\mathrm{NaNO}_{2}$ in the presence of dilute $\mathrm{HCl}$ at $0-5{ }^{\circ} \mathrm{C}$. The mixture was then heated to $75{ }^{\circ} \mathrm{C}$, followed by the addition of MWNTs to facilitate the $\mathrm{C}-\mathrm{C}$ coupling reaction with GO. This is well supported by FT-IR (Fig. 1a) where C-N bond formation $\left(1300 \mathrm{~cm}^{-1}\right)$ further supports the reaction between the MWNTs and GO. The broad peak in the range $3650-3250 \mathrm{~cm}^{-1}$ is the overlap of the $\mathrm{O}-\mathrm{H}$ and 


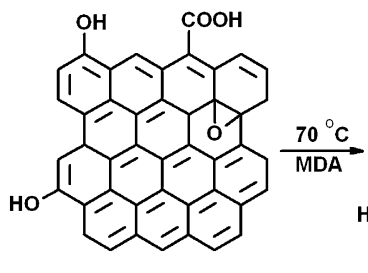

GO

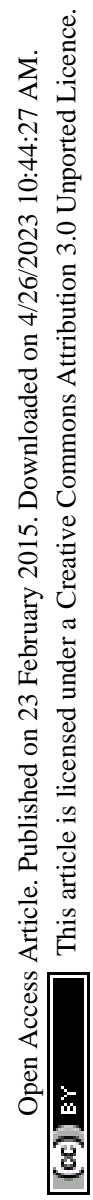

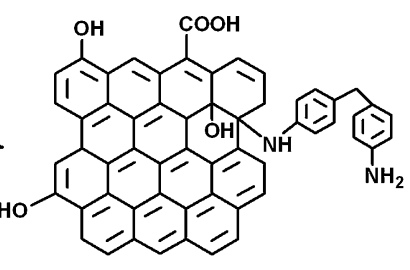

GO-NH $\mathrm{NaNO}_{2}$, dil $\mathrm{HCl}$ 0-5 ${ }^{\circ} \mathrm{C}$

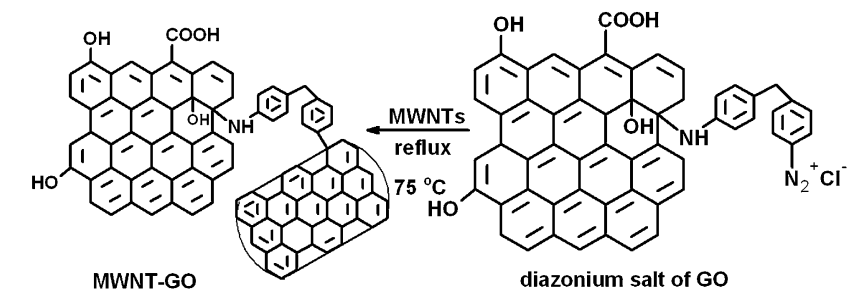

Scheme 1 Synthesis of MWNT-GO hybrid.
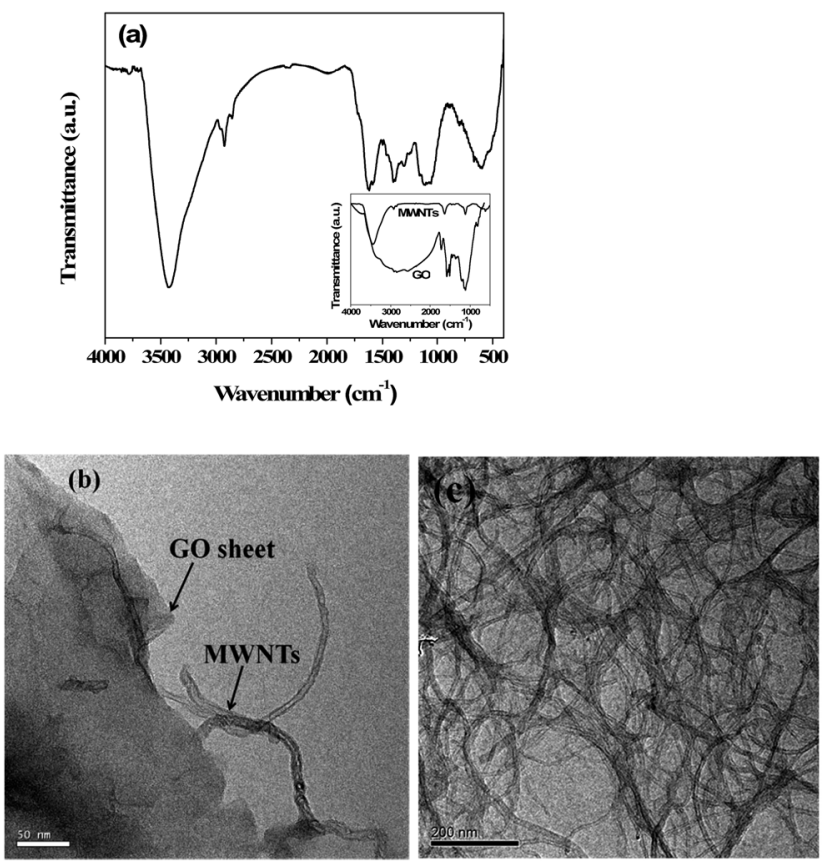

Fig. 1 (a) FT-IR spectra of MWNT-GO (inset shows the FTIR for GO-NH ${ }_{2}$ and MWNTs) (b) TEM micrograph of MWNT-GO and (c) TEM micrograph of entangled MWNTs.

$\mathrm{N}-\mathrm{H}$ vibrational frequencies. ${ }^{21}$ The peak at $2930 \mathrm{~cm}^{-1}$ corresponds to the $\mathrm{C}-\mathrm{H}$ stretching vibration. The HR-TEM images shown in Fig. $1 \mathrm{~b}$ and $\mathrm{c}$ further confirm this conjugation between the MWNTs and GO sheets.

\section{Phase morphology and selective localization of MWNT-GO in the blends}

The phase morphology of PA6-mABS (50/50, wt/wt) blends with or without MWNT-GO hybrid was studied by SEM. The mABS phase was etched with chloroform. ${ }^{25}$ The holes thus generated represent the etched out mABS phase as shown in Fig. $2 .{ }^{26}$
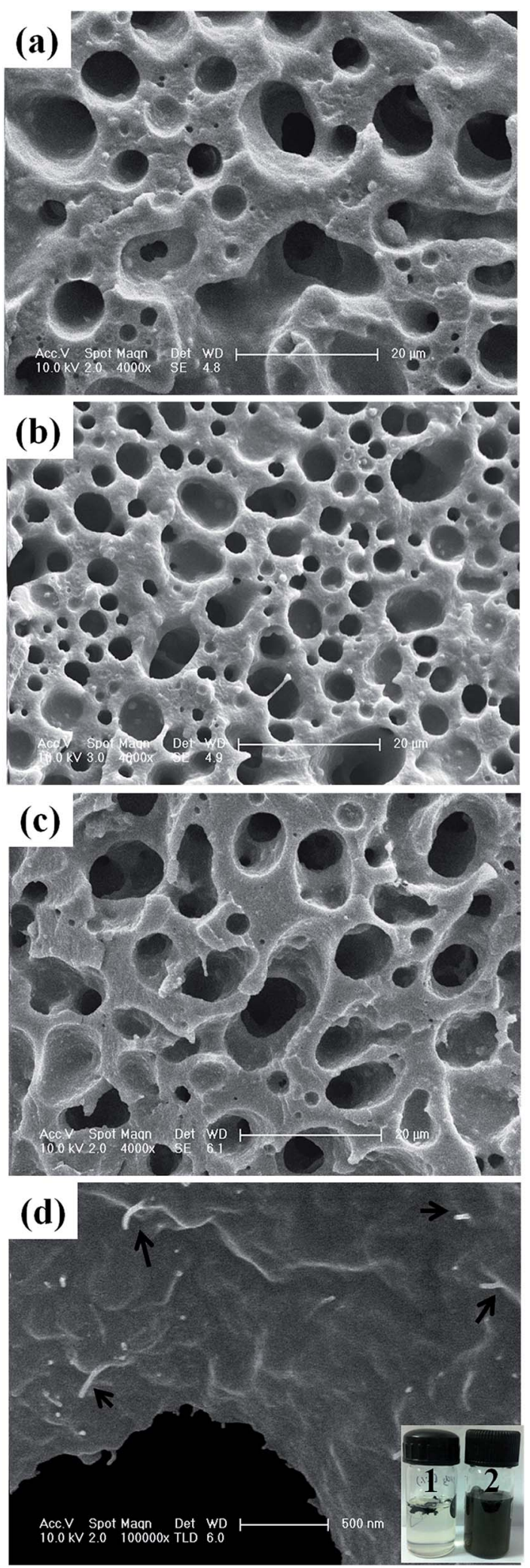

Fig. 2 SEM morphology of PA6-mABS (50/50, wt/wt) blends: (a) neat, (b) with 1 wt\% MWNT- GO, (c) with 2 wt\% MWNT-GO and (d) higher resolution images of (c) where the MWNTs are indicated as bright dots/ tubes. (Inset showing the selective localization of the MWNT-GO hybrid in the PA6 phase. Vial 1 corresponds to PA6-mABS blends with 2 wt\% MWNT-GO in $\mathrm{CHCl}_{3}$ and vial 2 corresponds to PA6-mABS with 2 wt\% MWNT-GO in formic acid.) 
It is well known that PA6 and mABS are immiscible in nature, hence, they present a coarse morphology. ${ }^{23}$ It is evident from Fig. 2 that mABS is randomly dispersed in the PA6 matrix. It is envisaged that the maleic anhydride groups in mABS can react with the PA6 during blending. ${ }^{27}$ However, as the maleic anhydride content in mABS is less than $0.7 \mathrm{wt} \%$ (as provided by the supplier) the extent of the reaction can be less. The possibility of the terminal amine groups in PA6 reacting with the carbonyl acid groups of GO cannot be ruled out either. The possible reactions are explained in more detail in the next section by spectroscopic evidence. The SEM images (Fig. 2a-c) show a seaisland structure of the PA6-mABS blends in the presence of MWNT-GO.

The extent of various possible reactions was assessed by FTIR (Fig. 3). The peaks at $2930 \mathrm{~cm}^{-1}$ for $\mathrm{C}-\mathrm{H}$ stretching, 2236 $\mathrm{cm}^{-1}$ for $\mathrm{C}-\mathrm{N}$ stretching, $1500-2000 \mathrm{~cm}^{-1}$ for polystyrene moieties and $1733 \mathrm{~cm}^{-1}$ for the $\mathrm{C}=\mathrm{O}$ group of maleic anhydride are evident in the FTIR spectra of mABS. ${ }^{25}$ The characteristic peak for free amine groups at $3292 \mathrm{~cm}^{-1}$ in the FTIR spectra for neat PA6 and the decrease in the intensity of this peak for the blends clearly suggest the reaction between the terminal amine groups in PA6 with either maleic anhydride groups in mABS or carbonyl groups on the GO. This is also supported by the peak at $3440 \mathrm{~cm}^{-1}$ corresponding to the hydrogen bonded amine group in the blends. In addition, the bands at $1633 \mathrm{~cm}^{-1}$ and 1539 $\mathrm{cm}^{-1}$ can be attributed to amide I and amide II, respectively, in the FTIR spectra for neat PA6. The bands at 1370, 1260 and 1205 $\mathrm{cm}^{-1}$ corresponding to amide III and $\mathrm{CH}_{2}$ wagging are noted in the FTIR spectra for neat PA6. ${ }^{25}$ In addition, the imide-five-ring deformation vibration appears at $749 \mathrm{~cm}^{-1}$.

In order to assess the selective localization of the hybrid structure in the blends, solution-dissolution experiments were performed. ${ }^{28}$ Typically, known amounts of the samples were dissolved in formic acid to remove the PA6 phase and in chloroform to remove the mABS phase from the blends. The vial containing formic acid turned dark after brief sonication indicating that the hybrid nanoparticles were selectively localized in

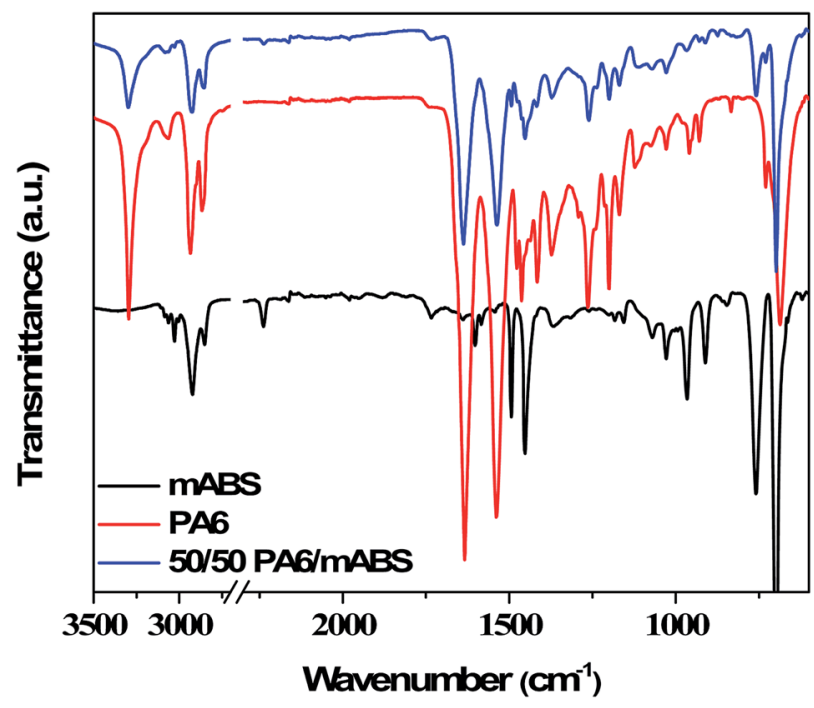

Fig. 3 FT-IR spectra of mABS, PA6 and 50/50 PA6-mABS blend. the PA6 phase of the blend. This was further supported by the fact that the vial containing chloroform showed no change in colour. Moreover, the higher resolution SEM images show the nanoparticles in the remaining PA6 phase (Fig. 2d) where bright dots represent MWNTs.

\section{State of dispersion assessed via melt rheology}

Melt rheology is a very sensitive tool to study the state of dispersion of the nanoparticles in a given polymeric matrix. ${ }^{21,29-32}$ Fig. 4a shows the storage modulus as a function of frequency for various blends. The storage modulus of PA6 is lower than $\mathrm{mABS}$ over the entire frequency range, while for the blends the storage modulus is in between that of the components. Blends with MWNT-GO hybrid particles exhibited a higher storage modulus with respect to the neat blends. In addition, the storage modulus scales with increasing fraction of MWNT-GO in the blends, indicating restricted motion of the macromolecules in the flow field.

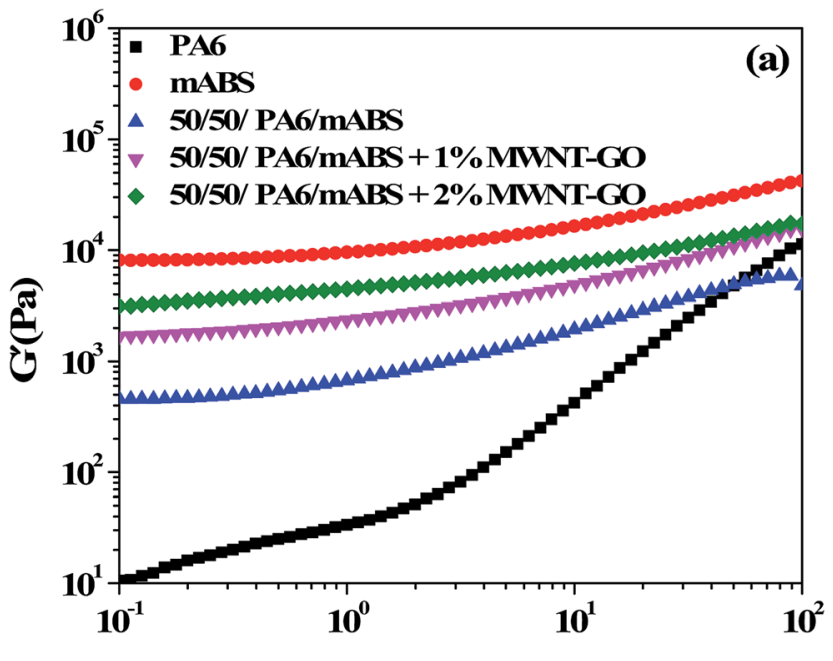

Angular frequency (rad/s)

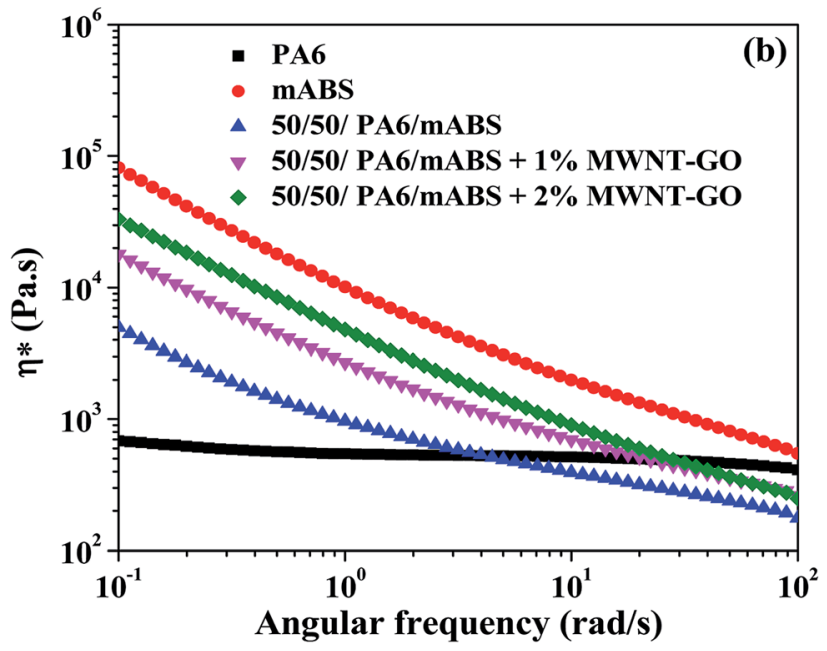

Fig. 4 Melt rheological properties: (a) storage modulus and (b) complex viscosity as a function of frequency for various blends and the constituent homopolymers. 

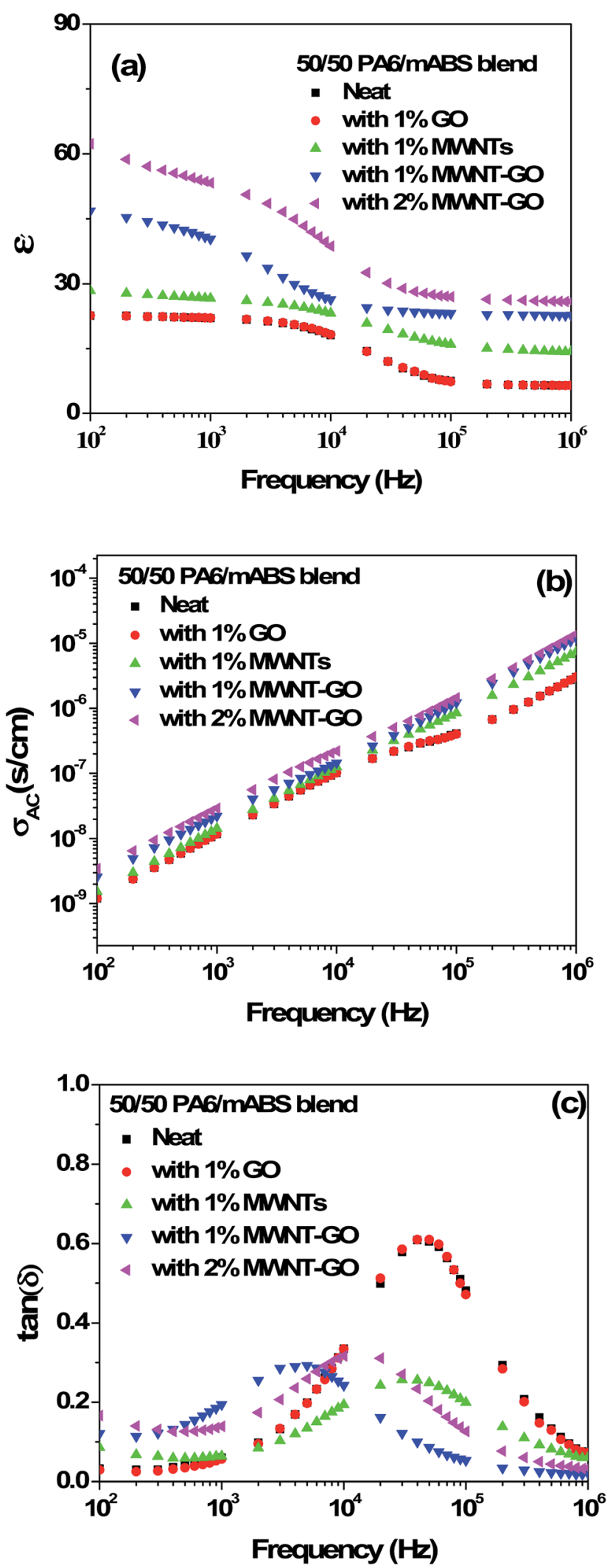

Fig. 5 (a) Dielectric constant, (b) AC electrical conductivity and (c) $\tan (\delta)$ as function of frequency for various blends investigated here.
The complex viscosity of the blends as a function of frequency (Fig. 4b) clearly shows a pseudo-solid nature and distinct yield stress in the lower frequency region. Neat PA6 exhibited Newtonian like behavior in the measured frequency range, whereas mABS and the different blends showed a strong shear thinning behavior with yield stress in the lower frequency region. ${ }^{25}$ The effect of particles on the flow properties is most prominent at lower frequencies where sufficient time is available for molecular relaxation. It was observed that the complex viscosity of the blends scaled with the fraction of MWNT-GO in the blends. ${ }^{24}$

\section{Dielectric properties}

Dielectric properties were measured at room temperature. Fig. 5a-c shows the dielectric constant $\left(\varepsilon^{\prime}\right)$, dielectric loss tangent $(\tan \delta)$ and $\mathrm{AC}$ electrical conductivity $\left(\sigma_{\mathrm{AC}}\right)$ for the various blends investigated here. The dielectric constant of the blend substantially increased with respect to the neat blend upon addition of MWNT-GO hybrid nanoparticles. For instance, at $100 \mathrm{~Hz}$, the neat blend showed a $\varepsilon^{\prime}$ of 22.5 , whereas the blends with $1 \mathrm{wt} \%$ MWNT-GO and $2 \mathrm{wt} \%$ MWNT-GO showed a $\varepsilon^{\prime}$ of 46.5 and 62.5 , respectively (Table 1 ). Interestingly, the hybrid MWNT-GO structures showed a higher dielectric constant compared to individual MWNTs (or GO). At $100 \mathrm{~Hz}$ the dielectric constants of the 50/50 PA6-mABS blend with $1 \mathrm{wt} \%$ GO and $1 \mathrm{wt} \%$ MWNTs were 22.5 and 28.5 , respectively, and as explained above, the dielectric constant of MWNT-GO was much higher. The dielectric constant is increased by the easy polarization of the electrons residing in the $\pi$ orbital of the MWNT-GO. The charge carrier originating under the electric field of the electrode migrates through the blend and accumulates at the interface as the relaxation time is different for the components. However, all the blends are insulating at room temperature (Fig. 5b). This is an ideal criterion for a dielectric material where the dielectric constant is higher but does not allow the free flow of electrons, thereby rendering insulating characteristics to the materials. This is also reflected in the dielectric loss tangent (Fig. 5c). The $\tan (\delta)$ value of the neat blend is 0.02 , and for the blends with MWNT-GO hybrid the loss tangent values are 0.12 (for $1 \mathrm{wt} \%$ MWNT-GO) and 0.16 (for $2 \mathrm{wt} \% \mathrm{MWNT}-\mathrm{GO}$ ) at $100 \mathrm{~Hz}$. So, the increase of the dielectric constant is attributed to the high interfacial polarization occurring at the interface of the blend and MWNT-GO. ${ }^{11,33}$ The dielectric constant progressively increases with decreasing frequency. The components which are insulating, MWNTs which are conducting and GO sheets that are insulating but are composed of an abundant $\pi$-electron cloud, lead to a large disparity in the dielectric constant. ${ }^{34}$ The increased dielectric

Table 1 Dielectric properties (at $100 \mathrm{~Hz}$ ) of 50/50 PA6-mABS blends

\begin{tabular}{lll}
\hline Blend & $\varepsilon^{\prime}$ & $\tan (\delta)$ \\
\hline 50/50 PA6/mABS neat & 22.5 & 0.02 \\
50/50 PA6/mABS with 1 wt\% GO & 22.5 & 0.02 \\
50/50 PA6/mABS with 1 wt\% MWNT & 28.5 & 0.08 \\
50/50 PA6/mABS with 1 wt\% MWNT-GO & 46.5 & 0.12 \\
50/50 PA6/mABS with 2 wt\% MWNT-GO & 62.5 & 0.16
\end{tabular}



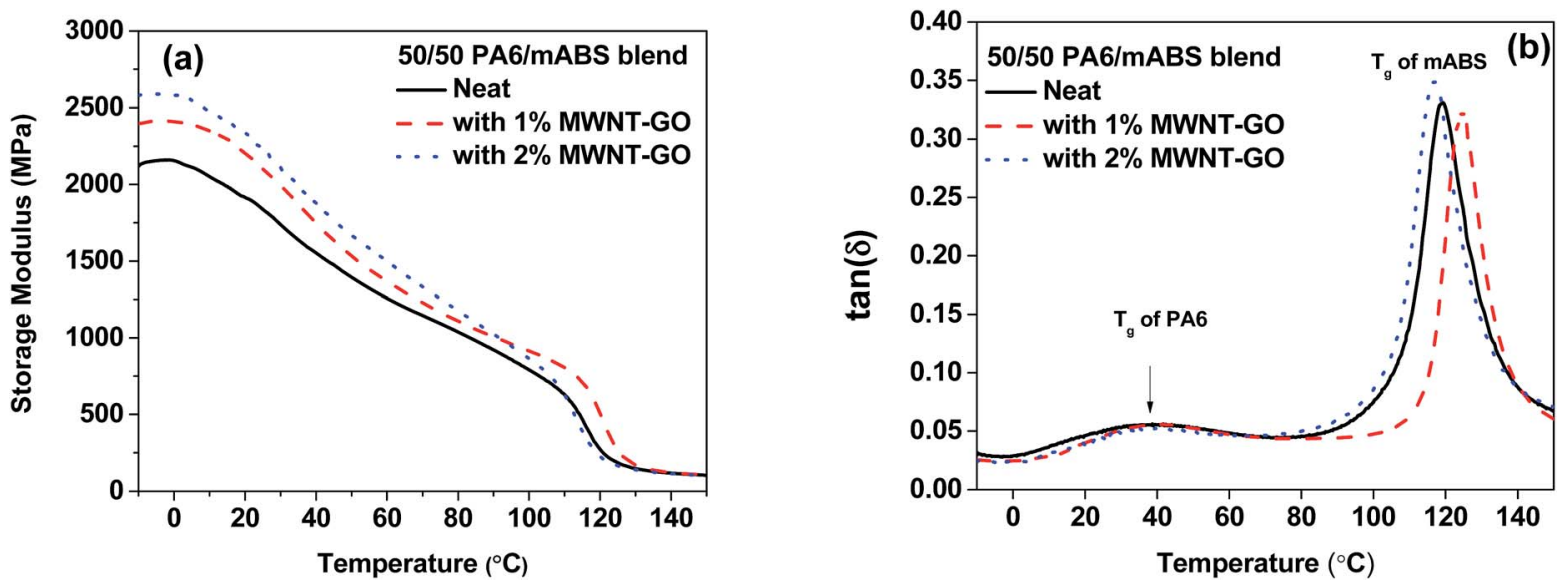

Fig. 6 Dynamic mechanical thermal analysis for the various blends investigated here: (a) variation of storage modulus and (b) variation of tan $(\delta$ ) with temperature.

dispersion seems to originate from the MWS effect (MaxwellWagner-Sillars polarization). This study clearly demonstrates that by anchoring MWNTs onto GO sheets, the dielectric constant of the material can be significantly enhanced, yet low dielectric loss achieved due to the restricted flow of electrons. It is a well-known fact that MWNTs enhance the dielectric constant of materials, however, also increase the dielectric loss due to leakage current. Hence, this unique strategy of anchoring MWNTs onto the GO sheets can trap charge at the interface of materials that show very different dielectric constants. Such materials can potentially be explored for capacitor applications.

\section{Structural behaviour of the blends: effect of MWNT-GO}

The reinforcing capability of the hybrid nanoparticles was evaluated by DMTA. ${ }^{28}$ Fig. 6 shows the variation in elastic storage modulus $\left(E^{\prime}\right)$ as a function of temperature. It is evident that in the lower temperature range $\left(-10-100{ }^{\circ} \mathrm{C}\right)$ the storage $E^{\prime}$ is significantly higher for the blends with MWNT-GO, in striking contrast to the neat blends. It is evident from the melt rheological investigations that the hybrid nanoparticles form a pseudo-solid like structure in the blend. Hence, the increase in the elastic modulus can be related to the reinforcing effects of the hybrid nanoparticles. Moreover, the enhanced interfacial adhesion between the functional moieties on the GO sheets and PA6-mABS can facilitate better stress transfer at the interface. Interestingly, from the $\tan (\delta)$ plots it can be observed that the $T_{\mathrm{g}}$ of mABS has decreased on addition of $2 \mathrm{wt} \%$ MWNT-GO, demonstrating the fact that the hybrid nanoparticles act as a plasticizing agent. The enhanced elastic storage modulus in the presence of MWNT-GO limits the possibility of chain scission. A more detailed investigation is required to get more insight in the plasticization effect in the presence of MWNT-GO hybrid particles.

\section{Conclusions}

In summary, a hybrid nanostructure of MWNTs anchored onto graphene oxide sheets was synthesized and melt blended with PA6-mABS blends. The hybrid nanoparticles were localized in the PA6 phase of the blend as confirmed by electron microscopic techniques. The hybrid nanostructures enhanced the dielectric constant of the blends by three fold in striking contrast to the neat blends and interestingly, exhibited low dielectric loss. This enhancement was attributed to the increased specific surface area of the conductor-insulator hybrid particles leading to increased interfacial polarization in the blend. The elastic storage modulus also improved with the addition of MWNT-GO hybrid structures. Such materials can be explored for capacitor type applications.

\section{Acknowledgements}

The authors gratefully acknowledge financial support from DST (India).

\section{References}

1 K. Yang, X. Huang, L. Fang, J. He and P. Jiang, Nanoscale, 2014, 6, 14740-14753.

2 C. Pecharromán, F. Esteban-Betegón, J. F. Bartolomé, S. López-Esteban and J. S. Moya, Adv. Mater., 2001, 13, 1541-1544.

3 Z. M. Dang, Y. H. Lin and C. W. Nan, Adv. Mater., 2003, 15, 1625-1629.

4 M. Sharma, S. Ranganatha, A. K. Kalyani, R. Ranjan, G. Madras and S. Bose, Mater. Res. Express, 2014, 1, 045301. 5 J.-Y. Kim, T. Kim, J. W. Suk, H. Chou, J.-H. Jang, J. H. Lee, I. N. Kholmanov, D. Akinwande and R. S. Ruoff, Small, 2014, 10, 3405-3411.

6 Q. M. Zhang, H. F. Li, M. Poh, F. Xia, Z. Y. Cheng, H. S. Xu and C. Huang, Nature, 2002, 419, 284-287.

7 R. Liu, J. Wang, Q. Li, S. Li, S. Zhang and X. Ding, J. Appl. Polym. Sci., 2014, 131, DOI: 10.1002/app.39975.

8 L. Wang and Z.-M. Dang, Appl. Phys. Lett., 2005, 87, 042903.

9 C. Yang, Y. Lin and C. W. Nan, Carbon, 2009, 47, 1096-1101.

10 J.-K. Yuan, S.-H. Yao, A. Sylvestre and J. Bai, J. Phys. Chem. C, 2011, 116, 2051-2058. 
11 P. Barber, S. Balasubramanian, Y. Anguchamy, S. Gong, A. Wibowo, H. Gao, H. J. Ploehn and H.-C. zur Loye, Materials, 2009, 2, 1697-1733.

12 M. Arbatti, X. Shan and Z. Cheng, Adv. Mater., 2007, 19, 1369-1372.

13 D. K. Das-Gupta and K. Doughty, Thin Solid Films, 1988, 158, 93-105.

14 P. Mishra and P. Kumar, Compos. Sci. Technol., 2013, 88, 2632.

15 M.-F. Lin and P. S. Lee, J. Mater. Chem. A, 2013, 1, 1445514459.

16 L. Xie, X. Huang, C. Wu and P. Jiang, J. Mater. Chem., 2011, 21, 5897-5906.

17 S. Bose, R. A. Khare and P. Moldenaers, Polymer, 2010, 51, 975-993.

18 C. Li, E. T. Thostenson and T.-W. Chou, Compos. Sci. Technol., 2008, 68, 1227-1249.

19 J.-Y. Kim, W. H. Lee, J. W. Suk, J. R. Potts, H. Chou, I. N. Kholmanov, R. D. Piner, J. Lee, D. Akinwande and R. S. Ruoff, Adv. Mater., 2013, 25, 2308-2313.

20 P. Xavier, K. Sharma, K. Elayaraja, K. S. Vasu, A. K. Sood and S. Bose, RSC Adv., 2014, 4, 12376-12387.

21 G. P. Kar, S. Biswas and S. Bose, Phys. Chem. Chem. Phys., 2015, 17, 1811-1821.

22 M. Kotal and A. K. Bhowmick, J. Phys. Chem. C, 2013, 117, 25865-25875.
23 S. Bose, A. R. Bhattacharyya, P. V. Kodgire and A. Misra, Polymer, 2007, 48, 356-362.

24 S. Bose, A. R. Bhattacharyya, A. P. Bondre, A. R. Kulkarni and P. Poetschke, J. Polym. Sci., Part B: Polym. Phys., 2008, 46, 1619-1631.

25 S. Bose, A. R. Bhattacharyya, A. R. Kulkarni and P. Pötschke, Compos. Sci. Technol., 2009, 69, 365-372.

26 S. Bose, A. R. Bhattacharyya, P. V. Kodgire, A. Misra and P. Pötschke, J. Appl. Polym. Sci., 2007, 106, 3394-3408.

27 L. Zhou, Y. Wan, X. Chen, S. Sun and C. Zhou, Polym. Compos., 2014, 35, 864-871.

28 S. Bose, A. R. Bhattacharyya, L. Häußler and P. Pötschke, Polym. Eng. Sci., 2009, 49, 1533-1543.

29 G. P. Kar, N. Begam, J. K. Basu and S. Bose, Macromolecules, 2014, 47, 7525-7532.

30 G. P. Kar, P. Xavier and S. Bose, Phys. Chem. Chem. Phys., 2014, 16, 17811-17821.

31 G. P. Kar, A. Bharati, P. Xavier, G. Madras and S. Bose, Phys. Chem. Chem. Phys., 2015, 17, 868-877.

32 A. Bharati, P. Xavier, G. P. Kar, G. Madras and S. Bose, J. Phys. Chem. B, 2014, 118, 2214-2225.

33 S. Y. Yang, K. Shin and C. E. Park, Adv. Funct. Mater., 2005, 15, 1806-1814.

34 J. W. Wang, Q. D. Shen, C. Z. Yang and Q. M. Zhang, Macromolecules, 2004, 37, 2294-2298. 